\title{
Literatura y folklore en las leyendas post mortem del $\mathrm{Cid}^{*}$ \\ Literature and Folklore in the Cid's Post Mortem Legends
}

\author{
Alfonso Boix Jovaní \\ Investigador independiente \\ alba_qu_bra@yahoo.com
}

\begin{abstract}
RESUMEN
Este artículo se centra en el análisis crítico de las leyendas póstumas del Cid desde un enfoque heurístico multidisciplinar al combinar el estudio de su poso ancestral folklórico con el apoyo de la comparatística, a fin apreciar el valor literario y antropológico de estos relatos. Un viaje al Más Allá que alcanza hasta finales del siglo XIX, cuando apareció una leyenda de claros tintes becquerianos cuyo análisis permite entender el presente artículo como un estudio sobre literatura medieval, pero también enmarcarlo dentro de las actuales tendencias del neomedievalismo al analizar la transmisión de topoi medievales y su plasmación en épocas recientes.
\end{abstract}

Palabras Clave: el Cid, leyendas, fantasma, Wild Hunt, folklore

Abstract

This article focuses on the critical analysis of posthumous legends of el Cid from a multidisciplinary heuristic approach by combining the study of its ancestral folkloric traces with the support of comparatistics in order to appreciate the literary and anthropological worth of these stories. A trip to the Great Beyond which will reach the end of the $19^{\text {th }}$ century, when a legend with a clear Becquerian influence appeared, the analysis of which will allow us to understand this article as a research on medieval literature but, also, to frame it within the current trends of neomedievalism by analysing the transmission of medieval topoi and their current expression.

KEYwORDS: el Cid, legends, ghost, Wild Hunt, folklore

FECHA DE RECEPCIÓN: 20/12/2019

FECHA DE APROBACIÓN: 03/03/2020

* El presente trabajo se inscribe en las actividades del Proyecto de I+D PGC2018095757-B-I00: Magia, Épica e Historiografía Hispánicas: Relaciones Literarias y Nomológicas II, del Programa Estatal de Generación de Conocimiento (MCIU/AEI/FEDER, UE) y de su línea de investigación sobre patrimonio inmaterial Las Tradiciones Cidianas, desarrollada en colaboración con el Consorcio Camino del Cid. 
Para seis de las siete rosas

que honran la tumba del Cid cada 10 de julio:

Juan, Jimena, Patricia, Goyo, José Luis y Javier

\section{INTRODUCCIÓN}

$\mathrm{E}$ 1 objeto de estudio que ocupará las siguientes páginas se antojará heterodoxo para el lector poco familiarizado con el mismo, y acaso lo considerará propio de una publicación de carácter esotérico y discutible validez científica. Sin embargo, la ilustre nómina de autores que han tratado las leyendas cidianas de ultratumba, directa o indirectamente, revelará cómo tal impresión sólo corresponde a un prejuicio infundado: bien como parte de la Leyenda de Cardeña (Entwistle, Smith), o por su propio valor literario y mítico (Galmés de Fuentes, Conde, Ramos, Lacomba), los episodios que han prolongado las andanzas del Campeador después de su muerte han interesado a los más reconocidos especialistas en los estudios cidianos. Mención aparte merece el maestro, quien, a salvo del más mínimo atisbo de imprudencia, protagonizó un apasionante diálogo con Carolina Michaëlis para enfrentarse a lo desconocido desde una perspectiva filológica y cultural (Menéndez Pidal, "Estantigua”; Michaëlis, "Réplica”).

Este artículo sigue, así, la estela de tan distinguidos predecesores al reivindicar la valía de sus trabajos, recuperándolos para este análisis de leyendas cidianas de ultratumba desde un enfoque heurístico multidisciplinar, pues los estudios críticos que sustentan estas páginas se complementarán con la perspectiva antropológica de eminentes folkloristas y el apoyo de la comparatística para recorrer, desde los textos medievales hasta los más recientes, la existencia de leyendas paralelas a las del Cid épico que lo convierten en protagonista de relatos sobrenaturales. Todo ello permitirá observar, junto al valor literario de las leyendas cidianas, cómo éstas se construyeron a partir de un poso folklórico ancestral que este Campeador difunto amalgama para, adaptándose a su público, seguir cabalgando en el imaginario colectivo por siglos, desde los primeros testimonios medievales a "El cuento del Cid", relato neorromántico de finales del siglo XIX apenas conocido por la crítica, y del que aquí se presenta su texto, convenientemente editado.

\section{LA APARICIÓN DE DON Diego LAÍneZ y Diego RodRígueZ}

El primer contacto del Cid con fantasmas se remonta a sus últimos días de vida $y$, aunque no haya alcanzado el grado de leyenda por carecer de la 
trascendencia de otros episodios que sitúan al Campeador como espectro, ${ }^{1}$ resulta sumamente interesante al transmitir una antiquísima creencia. Todo sucede en Valencia, cuando el Cid, hallándose acostado, recibe la visita de san Pedro advirtiéndole de su cercana muerte. Sin embargo, cuando Rodrigo explica tan extraordinaria visita a su familia y amigos, incluye una inesperada revelación que el lector ignora hasta ese momento (Primera Crónica General, 634, capítulo 952):

Et desto so muy çierto, ca bien ha mas de siete noches que visiones me siguen, ca veo mi padre Diego Laynez et a mi fijo Diego Ruyz, et cada vez que los veo, dizenme: 'mucho auedes morado aqui! trendos, et vayamosnos a las asonadas perdurables'.

Se trata de un pasaje precioso por su valor literario y antropológico al recoger aspectos folklóricos muy llamativos. En primer lugar, a nivel literario, existen testimonios antiquísimos de apariciones de difuntos en sueños y visiones nocturnas: en la Ilíada, Patroclo se aparece a Aquiles para, también, advertirle de su cercano fin (Canto XXIII, 62-108), e Ifftima se aparece a Penélope en la Odisea (Canto IV, 795-481). La tradición literaria se extiende hasta nuestros días, como se observa en las palabras que una muchacha pronuncia antes de ser sacrificada en un funeral vikingo, según una novela de Michael Crichton (Devoradores de cadáveres, 53):

La primera vez dijo: "Mirad, veo a mi padre y a mi madre". La segunda vez: "Mirad, veo sentados a todos mis parientes muertos". Y la tercera: "Mirad, veo a mi amo sentado en el Paraíso. El Paraíso es tan hermoso, tan verde... Con él están sus hombres y sus jóvenes. Me llaman, de modo que llevadme hasta él”.

\footnotetext{
${ }^{1}$ A lo largo del presente estudio, utilizaré los términos "fantasma", "espíritu" y "espectro" como sinónimos con el propósito de agilizar la lectura, de acuerdo con el significado popular de "figura o imagen incorpórea generalmente de una persona muerta que, en la creencia de algunas personas, se aparece a los vivos para asustarlos o recordarles alguna mala acción” (definición de "fantasma" según Lara Ramos, DEM). Por tanto, "fantasma" no debe entenderse stricto sensu, es decir, de acuerdo con la canónica interpretación de Myers y sus diferencias con respecto a las otras entidades (Human Personality).

${ }^{2}$ Estas palabras gozan de gran popularidad - el personaje Atreus la pronuncia en una versión del videojuego God of War e incluso aparece una variación de la misma en la reciente Thor: Ragnarok (2017), dirigida por Taika Waititi y protagonizada por Chris Hemsworth (Kelly, "The 13th Warrior") — gracias a su adaptación como hermosa oración vikinga en la versión cinematográfica de la novela, El guerrero no 13 (1999) dirigida por John McTiernan
} 
Aunque pertenecen a una novela moderna, estas palabras todavía recogen la idea de cómo los antepasados, ya muertos, llaman al que pronto va a reunirse a ellos, acaso actuando como una suerte de psicopompos. Pero, más allá de los textos que atestiguan esta creencia desde hace siglos, el pasaje cronístico del Cid aporta una información aún más interesante: la referencia a que, cuando el Cid acompañe a sus parientes, irán "a las asonadas perdurables", lo que coincide con una creencia nórdica que recoge la oración vikinga de Crichton, pues los grandes guerreros muertos, los einherir, combaten en el Valhalla mientras se preparan para el Ragnarök (Page, Mitos nórdicos, 61-63). Por supuesto, no estoy diciendo que la crónica sanchina recoja una creencia germánica o escandinava, pero su fondo es el mismo, quizá por ser una creencia propia de pueblos guerreros, o tal vez como un eco del antiguo pasado germánico del pueblo visigodo. A esta tradición de tintes paganos se añade la aparición de san Pedro, la cual corresponde, a su vez, a la creencia de la aparición de santos y ángeles en sueños (Joset, "Sueños y visiones"), cuya documentación es abundante y ya se encuentra en la Biblia con la petición a San José de que no repudie a María por estar encinta, o el aviso de las malas intenciones de Herodes a los Magos, por ejemplo ( $M t$ 1, 20-24 y 2, 1219 , respectivamente), y que se manifiesta incluso en el mismo Cantar de Mio Cid, donde san Gabriel anima en sueños al Campeador (404-412), aparición acaso influida por la del mismo arcángel a Carlomagno (Smith, "The Cid as Charlemagne", 516).

\section{EL JUdío QUE QUISO MESAR LA BARBA DEL CID}

Frente al resto de historias de ultratumba asociadas al Campeador que aquí presentaré, la aventura del judío y el cuerpo embalsamado de Rodrigo Díaz es la más divertida y, también, la menos bélica. Por cuestiones de claridad expositiva, sus características me obligan a analizar dicha aventura aquí separándola del resto para evitar que interrumpa la concatenación de los episodios

y protagonizada por Antonio Banderas: "He aquí que veo a mi padre, he aquí que veo a mi madre, a mis hermanas y mis hermanos. He aquí que allí veo al linaje de mi pueblo hasta sus principios. Y he aquí que veo que me llaman: me piden que ocupe mi lugar entre ellos, en los atrios de Valhalla el lugar donde viven los valientes para siempre" (en inglés, lengua original de la película, "Lo, there do I see my father. Lo there do I see my mother, and my sisters and my brothers. Lo there do I see the line of my people, back to the beginning. Lo, they do call to me, they bid me take my place among them in the halls of Valhalla, where the brave may live forever"). 
que destacan la faceta militar del Cid, lo que permitirá desarrollar un análisis comparativo desde una perspectiva diacrónica que refleje la transmisión de los principales motivos constitutivos de tales relatos.

El episodio del judío ante el cadáver del Cid es uno de los relatos que conforman la Leyenda de Cardeña, como refleja el hecho de que la puesta en escena, por así llamarla, resultará incomprensible a quien ignore que el cuerpo embalsamado del Cid fue trasladado al monasterio de San Pedro de Cardeña tras la evacuación de Valencia (1102) donde, en lugar de ser enterrado, permaneció sedente a lo largo de diez años, según el testimonio de la Leyenda no exento de ecos carolingios, como bien señaló Smith ("The Cid as Charlemagne”, 518-522; "La leyenda de Cardeña”, 513). Durante ese período habría tenido lugar este episodio, que así narra la Primera Crónica General (642-643, capítulo 961):

\section{Del miraclo que Dios mostro por el cuerpo del Çid Ruy Diaz et de commo fue soterrado.}

Cuenta la Estoria deste noble varon el Çid Ruy Diaz el Campeador, sennor que fue de Valencia, et dize assy, que diez annos estudo el su cuerpo assentado en aquella siella en el tabernaculo que el rey don Alfonso le pusiera; et cada anno, en tal dia commo el finara, el abbat don Garci Tellez et Gil Diaz mandauan fazer muy grant fiesta et dauan a comer et a uestir a muchos pobres, et ayuntauase y muy grant conpanna de todas partes de enderredor. Et acaescio assy vna vez, faziendo aquella fiesta, que se allegaron y muy grandes conpannas, et vinien $y$ muchos judios et moros por veer aquella estranneza del cuerpo del Çid. Et el abbat don Garcia Tellez auie por costunbre, quando fazie aquella fiesta, de fazer su predication muy noble al pueblo, et porque non cabien en la eglesia, salie siempre fuera a la plaça. Et el estando faziendo su sermon, diz que finco y vn judio en la puerta de la eglesia; et estando todos fuera por oyr aquel sermon, aquel judio entrosse dentro en la eglesia, et fuesse parar ante el cuerpo del Çid Ruy Diaz; et començol a catar en commo estaua tan noblemiente asentado et en commo tenie el rostro tan fermoso et la barba luenga et mucho apuesta, et tenie la espada en la mano siniestra et la derecha en las cuerdas del manto, assy commo lo el rey mandara poner, saluo ende quel camiauan cada anno los pannos, et tornauanle en aquella misma manera; et dize la estoria que quando aquel judio se paro antel Çid, auie ya siete annos que estaua en aquella siella. Et en toda la eglesia non estaua otro omne sinon aquel judio, ca todos estauan fuera, oyendo la predicaçion que el abbat fazie et mucho assessegados; et el judio quando se vio en su cabo, començo a cuydar et a dezir entre ssi mismo: «este 
es el cuerpo de aquel Ruy Diaz el Çid, de que dizen que nunca en toda su vida le trauo omne de la barba! quiero yo agora trauarle en ella et veer que sera lo que el me podra fazer». Entonçe tendio la mano por trauar en la barba del Çid, et ante que la mano huuiasse llegar al Çid, cayo la mano derecha de las cuerdas del manto et trauo en el arriaz del espada, et sacola fuera quanto vn palmo. Et quando esto vio el judio, ouo atan grant miedo que cayo atras de espaldas, et començo a dar muy grandes bozes, que quantos estauan fuera de la eglesia lo oyeron, et el abbat mismo ouo a dexar la predication, et entro en la eglesia; et fallaron aquel judio antel cuerpo del Çid tendido, et callara ya de dar bozes, et estaua tan quedo que semeiaua que era muerto. Et quando esto vio el abbat don Garcia Tellez, paro mientes al cuerpo del Çid, et vio commo tenia la mano derecha en el arriaz del espada et la espada sacada quanto vn palmo, et fue marauillado, ca la non solie tener siempre sinon en las cuerdas del manto. Estonces el abbat demando del agua, et echola al judio en el rostro, et recordo; et el abbat pregunto que que fuera aquello; et el judio començo a dezir todo lo quel acaesçiera. Quando esto oyeron el abbat et Gil Diaz et quantos y estauan, fueron marauillados, et fizieron grant clamor de grant plegaria a Dios porque tal virtud mostrara por el cuerpo del Çid, ca manifiestamiente paresçio que assy fue commo el judio dixo. Et desde aquel dia en adelante, estido el cuerpo del Çid en aquella manera, que nunca mas le pudieron mudar los pannos nin toller la mano del arriaz del espada, nin sacar la espada nin meterla mas en la bayna; et assy estudo tres annos, en que se cumplieron los $\mathrm{x}$ annos. Et despues destos $\mathrm{x}$ annos, cayosele al Çid el pico de la nariz; et quando esto vieron el abbat don Garçi Tellez et Gil Diaz, entendieron que dalli adelant non caye que el cuerpo del Çid estudiesse en aquel lugar, porque parescie feo; et ayuntaronse y tres obispos de las prouincias de enderredor, et con muchas missas et con muchas vigilias enterraron el cuerpo del Çid ante el altar, a par de donna Ximena su muger, ally o agora yaze.

Al menos que yo tenga noticia, nadie se ha dado cuenta hasta ahora de la similitud entre este Cid embalsamado y el personaje de la estatua antropomorfa funeraria que reacciona evitando una profanación, como sucede en la leyenda "El beso", de Gustavo Adolfo Bécquer, donde un joven capitán francés muere cuando intenta besar en los labios a la escultura de doña Elvira de Castañeda al recibir una fatal bofetada que le propina la estatua que la acompaña, la de su difunto esposo, don Pedro López de Ayala, quien evita así el sacrilegio con su guantelete de piedra. Podrían señalarse otros paralelos, como en "La ajorca de oro" del mismo autor, ${ }^{3}$ o la aparición del convi-

${ }^{3}$ Sobre el sentido de estas entidades en la obra becqueriana, véase el capítulo "Los fantasmas de piedra” en García-Viñó, Mundo y trasmundo, 105-130.

Medievalia 52:1, 2020, pp. 5-39 
dado de piedra en los donjuanes de Tirso de Molina y de Zorrilla, aunque, en estos casos, el movimiento de las estatuas supera ampliamente el mero gesto, tan sorprendente como aterrador, del brazo que reacciona castigando al profanador antes de que éste cometa su injuria. Este tipo de aparecido no queda limitado a la literatura española, sino que se encuentra también en la literatura inglesa, donde las estatuas de dos temibles guerreros van más allá de animar sólo un miembro, pues cobran vida totalmente en Man-Size in Marble, de Edith Nesbit (publicada en 1887), o en la ópera de Louis Joseph Ferdinand Hérold Zampa, donde la estatua que representa a Alisa de Manfredi amenaza al protagonista cuando éste intenta robarle un anillo, y que, con toda probabilidad, sirvió de fuente a Bécquer para "El beso" (Estruch, "Fuentes y originalidad”, 6-8). Quiero llamar la atención sobre el hecho de que siempre se trata de figuras funerarias, como si algo del espíritu del difunto se encarnase en la escultura, salvo en el caso de la estatua de Galatea que cobra vida en el antiquísimo mito de Pigmalión, antecedente de estos portentos aunque, en ese caso, la figura se convierte en humana.

En el caso del Cid, la estatua es reemplazada por el cuerpo embalsamado del Campeador, lo cual le otorga un realismo inalcanzable para cualquier escultura de la época, pues su apariencia transmite una idea de pervivencia tras la muerte, como si el cuerpo albergase todavía algo del alma que una vez lo animó. Ese proceso de conservación habría comenzado antes de la muerte del Cid, cuando él mismo, advertido por san Pedro de la cercanía de su muerte, ingiere un bálsamo mezclado con mirra que ayuda a preservar su cuerpo dándole apariencia de vitalidad (Primera Crónica General, 633-635, capítulos 952-953), ${ }^{4}$ lo cual servirá también para desbaratar a los almorávides en la batalla final, que estudiaré en el apartado siguiente. En este sentido, los ungüentos para su embalsamamiento cumplen la misma función - aunque no tan mágica - que la pócima utilizada por esta anciana (Montreuil, La Continuation de Perceval, 172-173):

Perchevaus la vielle regarde

Qu'a autre chose n'avoit l'ueil.

Et la vielle oste le vertueil

D'un des baraus, si en degoute

En sa palme ausi c'une goute

Plus clere que nule iaue rose.

\footnotetext{
${ }^{4}$ Se trata de nuevos elementos legendarios de probable influencia carolingia (Smith, "The Cid as Charlemagne", 512-513, 516-517).
}

Medievalia 52:1, 2020, pp. 5-39 
La vielle mie ne repose:

A la goute son doit atouche, Puis en froie celui la bouche A cui la teste avoit rajointe. Sor celui n'ot vaine ne jointe Qui lués ne fust de vie plaine, N'avoit plaie qui ne fust saine Ausi que s'ainc ne fust blechiez; Plus tost est en estant drechiez Que on ne peüst dire trois. A la poison fu li otrois Donez qu'ele fait mors revivre,

Car Dieus, qui ses amis delivre

D’infer et chiaus qu'il a amez,

En fu oinz et enbalsemez

Quant el sepulcre fu couchiez.

A quatre en a remis les chiés

La vielle et rendue la vie,

Car ele n'avoit d'el envie,

Et un autre la boche en froie:

Cil saut sus. Perchevaus s'esfroie

De che qu'il vit et regardoit: (5612-5639)

Esta magia, que mucho tiene de antinatural, es reemplazada por un proceso menos siniestro y más verosímil que, además, es más acorde para un caballero cristiano que iba a permanecer en el monasterio de San Pedro de Cardeña, y que remite a los milagros de los santos incorruptos, cuyos rasgos se habrían incluido en este relato en la Leyenda de Cardeña para acercarlo a los textos hagiográficos. A ello contribuye que el milagro no radique tanto en el sobrenatural movimiento del cadáver, sino que derive en la conversión del judío, pues "dize la estoria que aquel judio por quien Dios mostro aquella uirtud por el cuerpo del Çid, por esto que vio et porque gelo metio Dios en voluntad, conuirtiosse a la fe de Jhesu Cristo, et fizose batear, et pusieronle nombre Diego Gil" (Primera Crónica General, 643, capítulo 962). Sin embargo, el carácter milagroso se desplazará más tarde hacia la propia reacción del cadáver, en cuanto que la Crónica de Castilla (248) atribuirá su gesto a que, "ante que llegase a él la mano en la barua, non ge lo quiso Dios consentir, e enbió el spíritu en el Çid”, idea que recoge la Crónica de 1344 (capítulo DLXVI, 933) y que la Crónica abreviada (258, capítulo CLXIIII) altera ligeramente al 
señalar que "por la virtud de Dios, sacó el espada cuanto un palmo". Como se observa, la leyenda incrementó progresivamente sus tintes cristianos y hagiográficos al considerar una obra de Dios el amenazante gesto del Cid, atribución divina que no se menciona en la Primera Crónica General.

Por otro lado, esta leyenda establece una continuidad con la creencia de que nadie mesó jamás la barba del Cid que ya atestigua el Cantar de Mio Cid (3281-3286):

- ¡Grado a Dios, que cielo e tierra manda!

Por eso es luenga, que a delicio fue criada.

¿Qué avedes vós, conde, por retraer la mi barba?

Ca de cuando nasco a delicio fue criada, ca non me priso a ella fijo de mugier nada nimbla messó fijo de moro nin de cristiana, ${ }^{6}$

Resulta difícil saber si los versos del Cantar inspiraron el relato caragdinense o si éste surgió a partir de una creencia ya difundida. Esta segunda opción es viable, en cuanto que el judío hace referencia a la vox populi que afirma la inviolabilidad de la barba del Campeador, la que él mismo decide desafiar como acto sacrílego hacia un difunto. Por otra parte, la elección del judío como personaje humorístico no debe juzgarse desde perspectivas actuales: ciertamente, la figura del judío en la literatura medieval se presta a escarnio, cuando no abiertamente a ser objeto de venganza: sólo hay que leer los Miraclos de Berceo para constatar tal extremo. En el caso que nos ocupa, como digo, el papel del judío es humorístico, en efecto, pero debemos tener en cuenta que este milagro acaba con una conversión, por lo que, necesariamente, el ofensor del Cid no podía ser cristiano y, fuese moro o judío, quedaría en ridículo por su osada pretensión de mesar la barba de Rodrigo Díaz. De cualquier modo, y fuese por la razón que fuese, el escogido para llevarse un susto de muerte — nunca mejor dicho-y convertirse fue un judío, y esto,

\footnotetext{
${ }^{5}$ La Crónica de veinte reyes (243, Libro X, capítulo LXXXIIII) no menciona este milagro "porque en la su estoria se contiene de cómmo murió e lo que acahesçió a la su muerte, por esso non los pusimos aquí por non enbargar esta estoria”, mientras que el resto de testimonios cronísticos medievales (Crónica de Castilla, la Crónica de 1344 y la Crónica abreviada de don Juan Manuel), así como la Crónica particular del Cid, ofrecen relatos prácticamente idénticos al de la Primera Crónica General, aunque con algunas variantes que han sido meticulosamente estudiadas por Conde ("La difusión y las fuentes", 111-115), quien señala entre ellas la atribución del amenazante gesto del cadáver a una intervención divina.

${ }^{6}$ Cito el Cantar de Mio Cid en este artículo siempre a partir de la edición de Montaner.
} 
desde la perspectiva cristiana, es muy benevolente, en cuanto que acaba salvando su alma gracias al Cid.

\section{DE LA VICTORIA DESPUÉS DE MUERTO}

\section{A LAs Navas de Tolosa: los EJÉRCitos DE Ultratumba}

Antes del milagro del judío, pero manejando el mismo tema de la apariencia rediviva del Cid por su embalsamamiento, ${ }^{7}$ destaca la más famosa de todas las leyendas post mortem del Campeador: su victoria frente a los almorávides. Tan trágico como inspirador, el sacrificio del héroe constituye uno de los tópicos más longevos de la épica. Y digo sacrificio, que no muerte, en cuanto que esta última nos alcanzará a todos, mientras que el primero constituye un final heroico que perpetua la memoria de quien murió al aceptar conscientemente un destino fatal en pro de su pueblo: Patroclo ocupa el lugar de Aquiles y se enfrenta a Héctor, quien, más tarde, responderá con su vida ante el indómito pélida; Beowulf muere combatiendo contra un dragón, en claro paralelismo con la muerte de Thor ante Iormungand; Byrhtnoth y sus hombres sucumben en el campo de Maldon contra el invasor vikingo, y, aunque Roldán muere víctima de su propia hybris, también sirvió de inspiración a las tropas de Carlomagno, una inspiración no exenta de ciertas ansias de venganza.

En el caso de Rodrigo Díaz, y de acuerdo con la Leyenda de Cardeña, sus hombres no necesitaron apoyarse en la memoria de su señor muerto porque su propio cadáver encabezó la carga final contra los almorávides: sobre Babieca, sostenido por tablas y cuerdas, cabalgó al frente de ellos infundiendo terror al enemigo, que huyó despavorido al verlo, creyéndolo vivo.

De nuevo, el testimonio de la Primera Crónica General ofrece una versión de los hechos en un pasaje del capítulo 956, "de commo Bucar et los XXVI reyes de moros fueron desbaratados ante la çibdat de Valencia, por ayuda del apostol Sanctiago, despues de la muerte del Çid”:

Et quando fue a la media noche, pusieron el cuerpo del Çid, assy commo estaua con su siella, en su cauallo Bauieca, et ataron las forcaduras de las tablas

\footnotetext{
7 "Et el cuerpo del Çid fue guisado en esta guysa: primeramiente fue balsamado et vngido segunt que a contado la estoria, et finco tan yerta la carne et tan fermosa et el rostro tan fermoso et los oios abiertos et la barba luenga et mucho apuesta, que non a omne en el mundo, que lo non sopiesse et lo viesse, que cuydasse que era sinon biuo" (Primera Crónica General, capítulo 956, 636).
}

Medievalia 52:1, 2020, pp. 5-39 
con cuerdas muy bien; et con lo que estauan pegadas en los arzones, estaua el cuerpo tan derecho et tan egual que non semeiaua sinon que biuo era en la siella; et tenie calçadas unas calças entremezcladas de blanco et de prieto a redeziellas menudas, que non a omne en el mundo que non cuydasse que eran brafoneras, sinon quando pusiesse la mano en ellas; et uistieronle vna vestidura, fecha a manera de perpunte, de vna porpola de las nobles del mundo; et pusieronle su escudo al cuello, et en la cabeça vna capellina fecha de pargamino et pintada a sus sennales que non a omne que non cuydasse que era de fierro; et pusieronle su espada Tizon en la mano, et el braço atado et aguysado yuso de la uestidura, tan bien et tan sotilmiente que era marauilla en commo tenie la espada tan derecha e tan egual. Et yua del vn cabo el obispo don Geronimo et del otro cabo Gil Diaz quel guiasse el cauallo, assy commo el mandara. Et desque todo esto fue assy guysado, a la media noche abrieron vna puerta de la çibdat que es contra Castiella et esta puerta de la çibdat a nombre puerta de Roteros - et primeramiente salio Pero Bermudez con la senna del Çid et quatrocientos caualleros con el, que les non menguaua sortija; et despues sallieron las azemilas et todo el otro rastro; et desy sallieron otros quatrocientos caualleros, otrossi muy bien guisados; et en la çaga venie el cuerpo del Cid, et con el çient caualleros todos escogidos vno meior de otro, et a sus espaldas vinie donna Ximena con toda su companna et seyscientos caualleros en pos ella que guardauan a ella et a todo el rastro. Et sallieron tan callando et tan passo, que non semeiaua que yuan y diez caualleros. Et desque todos fueron fuera, era ya dia claro; et Aluar Fannez tenie sus azes ordenadas, et fueron luego ferir en los moros [... . Et tan grant fue el roydo et la buelta entre ellos que muy pocos dellos se pudieron acoger a las armas, mas tornaron las espaldas quien mas podie, et començaron a fuyr contra la mar. Et quando esto vio el rey Bucar et los treynta et seys reyes, fueron marauillados, ca bien les semeio que vinien y sessenta mill caualleros todos mas blancos que vna nieve; et uenia delante vno mas grande que todos los otros, et traye en la mano vna senna blanca et en la otra vna espada que semeiaua fuego; et fazie vna mortandat muy grande en los moros que yuan fuyendo, que tan espantado fue Bucar et los sus reyes, que començaron a fuyr et non touieron rienda fasta en la mar. Et estonçe la conpanna del Çid començaron a yr firiendo et matando en ellos. En esto el obispo don Geronimo et Gil Diaz fueron sacando el cuerpo del Çid et a donna Ximena et a su conpanna, et todo el otro rastro de las azemilas, de la angostura de la huerta todavia enderesçando su camino contra Castiella; et desque fueron fuera en vn llano, atendieron a la otra conpanna que yua en alcance. ${ }^{8}$

\footnotetext{
${ }^{8}$ Como sucede en el caso del milagro del judío, la Crónica de veinte reyes no presenta leyendas post mortem del Cid, y se limita a exponer que "Doña Ximena, su muger, e don Aluar Fanes
} 
Esta victoria póstuma, legendaria, resulta más grandiosa que la realidad histórica, por la que los almorávides permitieron que Jimena y sus tropas abandonasen Valencia portando el cuerpo del Cid. Aunque en modo alguno puede hablarse de una rendición ignominiosa, pues la viuda del Cid hizo cuanto estuvo en su mano y ni siquiera el rey Alfonso pudo ayudarle a mantener la plaza bajo su dominio (Historia Roderici, capítulo 76), la leyenda hizo que el Cid, vencedor y nunca vencido, lograse tras su muerte el colofón a su extraordinaria carrera militar, hasta el punto de figurar en el epitafio de su tumba caragdinense. ${ }^{9}$

La base de la leyenda, ese caballero muerto que engaña a su enemigo al hacerle creer que sigue vivo y protege la huida de su gente, encuentra paralelos en los dos relatos árabes de Rabīca Ibn Muqqadam y ${ }^{\mathrm{c}}$ Antar, cuyos cadáveres, 16 inertes sobre sus monturas, intimidaron al enemigo y protegieron la huida, respectivamente, de las mujeres de su tribu y sus hombres. Para Galmés de Fuentes ("La batalla vencida"; reed. La épica románica, 362-365) la similitud de estas leyendas con el relato cidiano apunta a su origen árabe, algo que ya advirtió Entwistle ("La Estoria del noble varón”, 209-210) al señalar que el moro converso Gil Díaz acompañó al difunto Campeador en su regreso a Castilla, y fue sucedido por el judío de la leyenda previa, Diego Gil, en la custodia de la tumba cidiana, lectura que ha desarrollado, recientemente, Ramírez del Río (La Leyenda de Cardeña, 93-145). Por supuesto, este Cid muerto carece de aspectos sobrenaturales, pero quedará investido de un aura de santidad gracias a la caballería angélica que acude en auxilio de las huestes cristianas y que lidera Santiago, como anuncia san Pedro en su nocturna aparición al Cid (Primera Crónica General, 633, capítulo 952). Ese carácter hagiográfico se acrecienta en la versión romancística de la leyenda (Durán, Romancero general, 570-571):

Miéntras se apresta Jimena con algunos de los suyos

Para partir de Valencia con el silencio noturno,

Myñaya leuaron el su cuerpo a Sant Pedro de Cardeña" (Crónica de veinte reyes, 243, Libro X, capítulo LXXXIIII; las crónicas posteriores presentan una narración muy similar, aunque la Crónica de 1344 (capítulo DLIX, 922) incrementa la cifra de caballeros celestiales en sesenta mil, número que aumenta en la Crónica particular y la Crónica de Castilla, donde alcanza los setenta mil (Crónica de Castilla, 242; Crónica del famoso cavallero, 607, capítulo CCLXXXIII).

9 "Cid Ruy Díez só, que yago aquí encerrado / e vencí al rey Bucar con treinta e seis reyes de paganos; / estos treinta e seis reyes, los veinte e dos murieron en el campo; / vencilos sobre Valencia, desque yo muerto, encima de mi cavallo. / Con esta son setenta e dos batallas que yo vencí en el campo. / Gané a Colada e a Tizona. Por ende Dios sea loado. / Amén" (Crónica del famoso cavallero, 679). Para un pormenorizado estudio del texto, véase Montaner, "El epitafio épico".

Medievalia 52:1, 2020, pp. 5-39 
Y los nobles castellanos, mas valerosos que muchos, Con fingidas alegrías velan los soberbios muros; Alvar Fañez de Minaya, Don Ordoño, y Don Bermudo, Para la batalla aprestan del Cid el cuerpo difunto. No le visten la loriga que él en las lides trujo, Por cumplir lo que mandó en su postrimero punto. De pergamino pintado le ponen yelmo y escudo, $Y$ en medio de dos tablones el embalsamado bulto, Y de un cendal claro verde vestido un tabardo justo, Al pecho su roja insignia, honor y asombro del mundo. Unas calzas de colores, guarnecidas de dibujo, En lienzo crudo pintadas, y ellas son de lienzo crudo. El derecho brazo alzado, al ménos cuanto se pudo,

En la mano su Tizona el limpio fierro desnudo.

D'esta guisa le aprestaron, y cuando aprestado estuvo

Pavor les dió de miralle, ¡ ital se muestra de sañudo!

Trujeron pues á Babieca, y en mirándole se puso

Tan triste, como si fuera más razonable que bruto.

Atáronle á los arzones fuertemente por los muslos,

Y los piés á los estribos porque fuesen más seguros.

Yá la lumbre del lucero, que por verle se detuvo,

Con su capitán sin alma salieron al campo juntos.

Donde vencieron á Búcar sólo porque á Dios le plugo,

Y acabando la batalla, el sol acabó su curso. ${ }^{10}$

En esta ocasión, el escenario se complementa con esa paralización solar de clarísima pátina milagrosa, pues trae a la memoria antecedentes como la victoria de Israel sobre los gabaonitas, cuando el Sol y la Luna suspendieron su avance (Jos 10,12-14) o el episodio donde Carlomagno logró alcanzar a un ejército musulmán en fuga gracias a que el Sol repitió tan extraordinario comportamiento (Chanson de Roland, 2447-2459, mss. O, ed. Martin de Riquer), lo cual podría suponer una nueva influencia carolingia, como las ya señaladas por Smith, si no sobre el texto sanchino, sí sobre la leyenda. ${ }^{11}$

\footnotetext{
${ }^{10}$ Siguiendo los criterios ecdóticos más aceptados en la actualidad, transcribo el romance recuperando la cesura, lo que me obliga a rectificar la letra primera capital de cada verso par, equivalente al segundo hemistiquio de cada uno de los versos que aquí se leen.

${ }^{11}$ Sobre este episodio de la Chanson de Roland y su repercusión en la literatura posterior, véase Rodríguez López, "El sol parado”, quien, por cierto, no recoge el romance que aquí aporto.
} 
Ambos textos, crónica y romance, presentan un milagro que aporta a la narración los tintes hagiográficos propios de la Leyenda de Cardeña, en cuanto que el cuerpo del Cid deja de ser un mero cadáver para convertirse en una reliquia capaz de convocar a una hueste celestial que incline la victoria a favor de su ejército. ${ }^{12}$ Aquí subyace un paralelismo, pues Santiago y el Campeador son los caudillos de sus respectivas huestes, lo cual remite a la imagen del Cid como enemigo irreductible del infiel y defensor de la fe, algo muy alejado de la realidad histórica pero muy conveniente a la hora de elevar al Campeador como símbolo de la Reconquista. El ejemplo por excelencia de este proceso de asociación e, incluso, identificación entre Rodrigo y el apóstol se halla en la puerta principal de San Pedro de Cardeña, donde la imagen del Cid a lomos de Babieca, matando y pisoteando moros, podría ser perfectamente confun18 dida con la de Santiago Matamoros.

La victoria del Cid después de muerto representa el episodio estelar de todo el mito cidiano, pero, a mi parecer, constituye tan sólo la primera fase de una evolución del Cid como personaje de ultratumba que adopta rasgos cada vez más extraordinarios para dejar de ser un mero cadáver que, casi como un espantapájaros, cabalga sobre Babieca, y convertirse en un verdadero espectro que, además, recogerá atributos de otros mitos muy conocidos en la cultura medieval europea, como se observará en el análisis de las siguientes leyendas. En efecto, varios siglos después de que la Leyenda de Cardeña concibiese la victoria póstuma del Cid, un nuevo testimonio atestiguaba su presencia en la jornada de las Navas de Tolosa (Yepes, Crónica general, capítulo XXV, 131-132):

Y no es cosa nueva ni sólo acontecida en esta casa que el conde Fernán González haga algún movimiento y se muestre en Castilla, favoreciendo a los cristianos, pues es cosa muy sabida y cantada en España de un caso notable que aconteció en aquella famosa batalla de las Navas de Tolosa, porque la noche antes del rompimiento hubo gran ruido por toda la ciudad de León, que parecía

\footnotetext{
12 "Dans le chapitre CLIX, le Cid est décédé et ses ordres ont été exécutés: son corps se trouve sur son cheval, 'ssemejaua que yua biuo', et ses troupes se préparent à affronter celles de Bucar: 'E salieron de Valençia [...], e ordenaron sus azes e fueron ferir en los moros'. Après cette succession de prétérits, simple chronique des faits, surgit lélément merveilleux, précédé de son explication: 'E por la voluntad de Dios aparesçio el apostol Santiago e fueron los moros vençidos'. [...] le critère sur lequel s'établit la véracité du récit passe du poids de la chronologie à l'explicitation de la causalité. À l'expression de la causalité sajoute ici celle de la volonté de Dieu, qui se manifeste ici dans toute sa puissance: les paroles de saint Pierre trouvent ici enfin leur pleine réalisation" (Lacomba, "Trois miracles cidiens", 182).
}

Medievalia 52:1, 2020, pp. 5-39 
pasaba por ella un gran ejército, el cual llegó al real monasterio de San Isidoro. Dieron golpes a la puerta y dijeron a un clérigo que estaba velando en la iglesia, que los capitanes de los que allí venían eran el conde Fernán González y el Cid Ruiz [sic] Díaz, y que iban a llamar al rey D. Fernando I, que estaba enterrado en San Isidoro, para que se hallase en la batalla. Túvose cuenta con aquel ruido y asonada de armas, y después, por buena cuenta, se halló que otro día fué el rompimiento de aquella famosísima y gloriosísima batalla en que el rey don Alonso, llamado el VIII, venció infinitos millares de moros de aquende y allende, que como una avenida grande habían cubierto a toda España. En este día mostró nuestro Señor lo que quería a estos reinos, y se vieron estos milagros patentes y claros (que no son de mi historia), y por eso la Iglesia de España celebra tanto esta victoria. La noche, pues, que precedió a este tan señalado día, permitió Dios que se representasen aquellas visiones en León, para que se entienda que las personas a quienes la vanidad de los gentiles llamaba antiguamente héroes, y el mundo ha tenido por hombres excelentes, tienen cuidado en el cielo de los negocios de importancia de la tierra. $\mathrm{Y}$ aunque realmente no se hallaron presentes los cuerpos, pero como las almas deseaban el buen suceso y le pedían a Nuestro Señor, hízose aquel movimiento y ruido sensible, para que echemos de ver la vigilancia y el deseo que ellos tienen de favorecer a España y el que la Majestad Divina muestra de oírles en semejantes ocasiones.

En un excepcional estudio sobre este suceso, Ramos ("El Cid y Fernán González”) presenta una nueva versión ovetense del mismo, firmada por el notario apostólico Tirso de Avilés, donde el Cid y Fernán González despiertan a los sacristanes de la iglesia de San Salvador porque desean orar y ver las reliquias que allí se guardan. Asombrosamente, los sacristanes se niegan "por ser de noche", pero los dos legendarios caballeros piden entonces que transmitan al rey Alfonso VIII que ambos acudirán a la cita de Las Navas.

Estas tropas cristianas de ultratumba guardan claras semejanzas con las diversas manifestaciones del motivo E501 Wild Hunt del conocido Index de Thompson: bajo este nombre genérico se integra toda una pléyade de ejércitos fantasmales del folklore europeo y hasta norteamericano ${ }^{13}$ conocidos bajo nombres tan siniestros como Wilde Jagd, Armée Furieuse o Wütendes Heer ${ }^{14}$

${ }^{13}$ Sobre los ejércitos de ultratumba en el folklore de los nativos norteamericanos, véase Houston ("Ghost Riders").

${ }^{14}$ Lisón Tolosana se refiere a "la Wilde Jagd o caza salvaje (wild hunt, chasse sauvage), conocida también como exercitus antiquus, esercito furioso, Wüstichend Heer, mesnie furieuse, mesnie Hellequin en España, Italia, Alemania, Inglaterra y Francia, espacio geográfico que, bajo esta

Medievalia 52:1, 2020, pp. 5-39 
(Wotan, el escandinavo Odín, es una deidad muy asociada a estos ejércitos espectrales) ${ }^{15}$ A lomos de caballos fantasmales y habitualmente precedidos por los temibles hellhounds negros y de ardientes ojos rojos, los espectros de guerreros irrumpen en los cielos envueltos en la ventisca y tormenta (Lecouteux, "Chasse Sauvage”, 23 y Chasses fantastiques, 183-185) que presagian su llegada, arrasan campos, cosechas e incluso vidas, pues grave riesgo corre quien tenga la desgracia de encontrarse con estas hordas fantasmales. Sus leyendas, ya documentadas en el medievo —especialmente gracias a Ordericus Vitalis y Walter Map-, ${ }^{16}$ se encuentran todavía muy arraigadas en toda la Europa celta, y aún hoy se escuchan relatos sobre manifestaciones tan dispares como los niños muertos sin bautizar de Perchta que rondan por la Selva Negra o la Santa Compaña, la Güestia y la Estantigua, propias del centro y norte de España (principalmente, la cornisa 20 cantábrica y León), donde el poso cultural celta es más profundo que en el resto del país. Como la Santa Compaña, la Güestia es una procesión de difuntos que deambula silenciosamente por las noches, visitando, cual heraldos de la muerte,

dimensión narrativa, configura una vasta área cultural” (La Santa Compaña, 19). Por su parte, Lecouteux enumera los nombres de "Chasse Infernale, Chasse Furieuse, Chasse Sauvage, en allemand: Wilde Jagd ou Wildes Heer, Wütischend Heer, Wütendes Heer, ou bien encore Mesnie furieuse, Chasse Arthur, Chasse Gallery, etc." ("Introduction", 10).

${ }^{15}$ La identificación de Wotan-Odín con el caudillo de estas hordas es dudosa. Para Lisón Tolosana "En el siglo x se había consolidado ya, después de centurias de gestación entre los pueblos germánicos, una peculiar mitología épico-guerrera presidida por Tîwaz supremo dios de las batallas. Wotan, rey entre los muertos, suplantó a Tîwaz y dirigió a las almas, en viaje nocturno, al otro mundo. Wotan, a su vez, precedió a Odín, dios de la guerra, de los muertos y de la inspiración. Éste adquirió, por su parte, de Wotan el rol de psychopompos: a la noche, volando o a caballo por el aire guiaba a las almas de los muertos que en procesión nocturna se dirigían de éste al otro mundo. Poco más tarde, Odín viene ya asociado en el folclore germano a la leyenda de la Wilde Jagd o caza salvaje" (La Santa Compaña, 19). Sin embargo, la conexión con Wotan no resulta concluyente, pues "dans le nord de l'Allemagne existait une tradition où le Chasseur infernal, non le meneur de la mesnie Hellequin, s'appelait Wode, ce nom devant être compris comme l'expression d'un tumulte: der Wütende; les philologues comme Loccenius ont rapproché et confondu les deux cohortes nocturnes, donnant au meneur des revenants le nom du Chasseur maudit, Wode, ce que facilitaient les traditions savante et mythologique: dans la mythologie germano-scandinave, Odin est le maître des revenants, draugadrottinn; son nom a la même signification que le bas-allemand Wode. C'est donc essentiellement sur une interprétation philologique que repose l'attribution à Odin de la cohorte des morts. [...] Nous avons dit 'essentiellement' car il n'est pas exclu que le vulgaire ait déjà fait le rapprochement, ce que tendrait à nous faire croire Loccenius" (Lecouteux, "Chasse Sauvage”, 30). Para una revisión más amplia del papel de Odín como caudillo de la Wild Hunt, véase Lecouteux, Chasses fantastiques, 175-204 y Ryan, "Othin in England”, especialmente 472-474.

${ }^{16}$ Véanse especialmente los estudios de Lecouteux (Chasses fantastiques, 81-124) y Vàrvaro (Apparizioni fantastiche). 


\title{
Alfonso Boix Jovaní
}

las casas de quienes pronto saludarán a la Parca, pero su nombre remite a su violento origen germánico, ya que güestia tiene su raíz etimológica en "hueste", como la Estantigua ("hueste antigua"), ${ }^{17}$ según ratifican diversos testimonios medievales que la asocian, tras la cristianización del mito, a lo demoníaco: ${ }^{18}$

\author{
Los vassallos del conde tenien se por errados, \\ eran contra el conde fuerte miente irados; \\ eran de su señor todos muy despagados \\ por que avian por fuerça sienpre d'andar armados.
}

Folgar non les dexava nin estar segurados, dizien: "Non es tal vida si non pora pecados, que andan de noche e dia e nunca son cansados, el semeja a Satan e nos a sus criados.

\section{Por que lidiar queremos e tanto lo amamos, nunca folgura avemos si almas non sacamos}

17 "Si le motif de l'armée fantôme [...] parait avoir perdu tout contenu militaire dans les formes modernes de la légende et de la croyance (les processions de morts de l'Espagne du Nord n'ont plus rien à voir avec une armée), ce sont toutefois le terme guerrier de 'hueste' et ses dérivés ('huestia', 'güestia', etc.) qui, parallèlement à celui de 'Santa Compaña', continuent à désigner, en particulier dans les Asturies, la nocturne et fantastique apparition” (Delpech, 'Chevalier fantôme', 74). Para Lisón Tolosana, "Estadea y estantigua son los términos que conectan más directamente con la dimensión marcadamente tenebrosa de la leyenda germánica; son, después de todo, derivaciones lingüísticas de términos medievales. Un tropel de extraños espíritus nocturnos aterrorizan, maltratan y se llevan por el aire en su revuelo aciago al desprevenido que encuentran en su interminable camino" (La Santa Compaña, 78).

${ }^{18}$ Para Lisón Tolosana, "el psychopompos Odín fue pronto cristianizado pasando a ser el demonio quien, con estrépito y terror, guiaba a la procesión nocturna de muertos camino de su mansión eterna" (La Santa Compaña, 19). Pese a que la identificación del dios escandinavo con el caudillo de estas hordas es dudosa, eso no afecta a la lectura demoníaca de estas presencias, que se confirma en la Exposición de la doctrina cristiana (Walter, "Hellequin, Hannequin”, 36-37), donde la mesnie está compuesta por demonios que cabalgan, aunque la cristianización ofrece otra adaptación del antiguo mito en el caso de los fallecidos prematuramente: "La plupart de ces défunts relèvent des morts prématurés et des trépassés mécontents de leur sort, cause de leur errance post mortem. En réinterprétant cette cause, l'Eglise récupère et christianise la croyance: les revenants sont des pécheurs, des âmes du purgatoire ou des damnés. Une fois ce postulat bien établi, l'Armée infernale se prête aussi à une interprétation et à une critique politiques, elle entre dans le grand cycle de la punition du péché qui relève elle-même d'une pédagogie de la peur, celle que nous retrouvons aussi dans le Lai du Trot et dans le Specchio della vera penitenza de Passavanti" (Lecouteux, "Chasse Sauvage", 22).

Medievalia 52:1, 2020, pp. 5-39 


\section{a la ueste antigua a aquellos semejamos,}

ca todas cosas cansan e nos nunca cansamos.

(Poema de Fernán González, cuadernas 336-338) ${ }^{19}$

Este valioso pasaje del Poema de Fernán González remite al carácter militar de los orígenes del mito, la Wild Hunt, pues son guerreros quienes aquí se comparan con la Estantigua. Menéndez Pidal ("Estantigua", 6-7) destaca el carácter demoníaco de la Estantigua en el verso "Asemeia a Satanas, e nos a los sus pecados" (cito por Menéndez Pidal; énfasis suyo), pero olvida que pertenece a una cuaderna distinta a la que menciona a la Estantigua, en la que la atmósfera militar es evidente y la identificación con el ejército de ultratumba es obvia, pues, "por que lidiar queremos", los guerreros van arrancando almas 22 ("si almas non sacamos"), como la Wild Hunt en su incontenible avance, de ahí que "a la ueste antigua a aquellos semejamos”. Mi afirmación halla sostén en las acertadas palabras de Carolina Michaëlis ("Réplica”, 15-16), ${ }^{20}$ quien señala la conexión de Wotan con Santiago e incluso la función del dios nórdico como arrancador de almas y su consiguiente demonización:

Quando no primeiro seculo da tardia christianização, o Pantheon germanico foi derribado (718 a 804), as divindades e muitas crenças, praticas e costumes seculares passaram, como em toda a parte, para a nova religião, convertidas pela actividade consciente da egreja e a acção inconsciente do povo. Precipitadas no abysmo, deuses e deusas, espiritos e duendes transmittiram ao filho de Deus, á Virgem, aos apostolos e aos sanctos, todos os seus mesteres innocuos e poeticos, e ao Satanas (que até então lhes fóra desconhecido) os maleficios e todos os actos funebres e terrorizantes. Wuotan, transformado em venator infernalis, e substituido posteriormente pelo principe do inferno, continuou então a vaguear, entre nuvens, á caça de almas, como chefe das ostes aereas que se degladiavam entre ruidos e phenomenos igneos [...]. Que a Morte, divindade subordinada a Hel e Wuotan, tomasse aqui e acolá —não só na Galliza e nas Asturias, mas tambem na Baviera — o logar do caçador de almas, e que a guerra

19 Cito por la edición de Juan Victorio.

20 El artículo "Estantigua" del maestro es eminentemente filológico desarrollando dubitativamente la etimología de "Estantigua" a partir de "hostis antiquus" y, en resumen, plantea en su estudio un alejamiento del origen germánico de la Estantigua, postura que rebate impecablemente Carolina Michaëlis de Vasconcelos en su "Réplica" al combinar el enfoque filológico con el antropológico, y confirmando el origen de la procesión española en las diferentes versiones germánicas de la Wild Hunt.

Medievalia 52:1, 2020, pp. 5-39 
e caçada se diluisse em cortejo, procissão e dança, cruzando-se com outras lendas e aproveitando partes do apparato tragicomico que as apparições de espiritos, espectros e almas costumam empregar, não pode surprehender ninguem que se occupe d'estes assumptos.

La cuestión sobre quién es el caudillo de estos ejércitos es secundaria, pues lo que nos concierne no es su nombre, sino su labor, y llevarse el alma de quienes encuentren a su paso sería herencia de ese pasado mitológico germánico, por lo que la explicación de Michaëlis es totalmente plausible, y aún más si se tiene en cuenta el enciclopédico caudal de datos adicionales que aporta en su "Réplica" para ratificar las raíces germánicas de la Estantigua. Es más: tradicionalmente, ésta es una hueste voladora, como sus paralelos centro y noreuropeos, ${ }^{21}$ pero la cita del Poema de Fernán González indica que se desplaza a pie, como la Santa Compaña, lo cual ofrece una imagen de la Estantigua muy cercana al ejército que encontramos en la visita del Cid y Fernán González a San Isidoro y San Salvador, cuyo ejército constituye un estadio intermedio entre la Wild Hunt y las procesiones de difuntos al combinar el elemento militar de la primera con la visita a pie de las últimas. No constituye, además, la única mención en la literatura española de esa clase de ejército, pues, de nuevo, Bécquer describe el mismo tipo de tropa en "El Monte de las Ánimas” (Boix, “Cacería fantástica”), lo cual refleja cómo los versos del Poema de Fernán González no fueron una mera invención de su poeta, sino que transmiten una tradición que pervivió a lo largo de siglos.

Estamos, a tenor de sus características, ante un ejército de ultratumba muy relacionado con la Wild Hunt, pero que Thompson clasifica como E502: "The Sleeping Army. Soldiers killed in battle come forth on occasions from their resting place (hill, grave, grotto) and march about or send their leader to do so", y que Lecouteux (Chasses fantastiques, 45) describe como "des morts qui poursuivent le combat après leur décès”. En este caso, la identificación resulta incuestionable, especialmente en el caso de la visita a León, en cuanto que no sólo Fernán González y el Cid han abandonado el sueño de los justos "occasionally" (con motivo de la batalla de Las Navas), sino que van a despertar al rey Fernando. Sin embargo, hay influencias del mito de la Wild Hunt, como la conversación de los muertos con los vivos, algo que no se da en los ejércitos

21 "Efectivamente en la estantigua se oyen ecos del estrépito bélico del antiguo ejército hispano y de la agresiva furia de la mítica caza salvaje sobre caballos voladores” (Lisón Tolosana, La Santa Compaña, 85). 
del tipo E502, ${ }^{22}$ un silencio que sí se cumple en el poema Las Navas de Tolosa (1594), de Cristóbal de Mesa, donde aparecen incontables tropas de ángeles, santos y héroes cabalgando por los cielos, y, entre ellos,

Desde una excelsa nube el Cid combate, y bárbaros sin cuento a tierra abate.

Resplandecientemente armado, el claro conde

Fernán González, lustre de Castilla, en el aire parece, desde donde

postra más de una pérfida cuadrilla. ${ }^{23}$

Con suma cautela, Ramos ("El Cid y Fernán González", 63) plantea la posibilidad de que este último texto sea la fuente que inspiró los relatos de Yepes y Avilés. En efecto, los tres escritos son muy cercanos en datación, pero las diferencias entre el texto de Cristóbal de Mesa y los de Yepes y Avilés son evidentes y, aunque no deba descartarse el recuerdo de la Sleeping Army / Wild Hunt en el ejército celestial de Mesa, como tampoco en las apariciones de Santiago en batalla, ${ }^{24}$ sus rasgos cristianos eclipsan la influencia germánica, pues los versos de Las Navas de Tolosa remiten a creencias ya presentes en la Biblia, donde aparecen "los jinetes blancos que en varias ocasiones guían y enardecen al ejército de Judas Macabeo", como Ramos ("El Cid y Fernán González", 56) señala con su proverbial perspicacia, entre otros muchos ejemplos bíblicos y medievales que aporta.

Por su parte, las visitas nocturnas del Cid y Fernán González comparten múltiples rasgos que las vinculan entre sí pero que, contrariamente, evidencian sus discrepancias con los versos de Mesa: las dos primeras muestran al Cid y Fernán González marchando juntos en la víspera de la batalla, mientras que el poema relata su intervención en tan crucial choque; los escenarios urbanos se oponen al campo de batalla de Las Navas, donde unas tropas aparecen por los aires, aspecto extraordinario que no se menciona al presentarse el ejército fantasmal en las calles de Oviedo y León, que remite, más

\footnotetext{
22 "Nous retiendrons un détail qui distingue ces armées de morts de la Chasse infernale: le spectateur n'entre pas en contact avec les revenants, il n'y a pas de dialogue, pas de révélations, pas de demande de suffrages ou de réparations" (Lecouteux, Chasses fantastiques, 47).

${ }^{23}$ Cito por Ramos ("El Cid y Fernán González", 62).

${ }^{24}$ Para Delpech, "le motif de l'armée fantôme, qui semble n'avoir prévalu que dans certaines zones périphériques, a été absorbé dans le mythe national des interventions guerrières des saints cavaliers et de leurs cohortes célestes (la plus fameuse étant bien sûr celle de saint Jacques à la bataille de Clavijo)" ("Chevalier fantôme”, 74).
}

Medievalia 52:1, 2020, pp. 5-39 
bien, a una peregrinación — como se observa, especialmente, en la visita a San Salvador - y trae a la mente el paseo nocturno de la Santa Compaña, con los tintes cristianos quedan más difuminados, si bien la atmósfera reconquistadora permanece. Estas visitas, por cierto, se producen de noche, lo cual corresponde al cronotopo nocturno, que se cumple en muchas visitas de estos ejércitos fantasmales. ${ }^{25}$ Las visitas a estos lugares sagrados, además, guardan otros elementos comunes con el ancestral mito celta, pese a que las múltiples versiones de estas procesiones de difuntos hacen difícil encontrar rasgos absolutamente iguales entre todas ellas: Walter Map, en De Nugis $\mathrm{Cu}$ rialium, afirma que el ejército infernal se desplaza en silencio (Lecouteux, "Chasse Sauvage", 21), lo que coincide con otras manifestaciones, como la Santa Compaña, mientras que la Mesnie Hellequin, una de sus versiones más populares, suele ir provocando un alboroto escandaloso, como el que destaca Yepes al afirmar que "hubo gran ruido por toda la ciudad de León". También es habitual que estos ejércitos y procesiones vayan comandados por héroes y caudillos legendarios (Lecouteux, "Introduction", 10; "Chasse Sauvage", 22), lo cual se cumple en Fernán González y el Cid.

Sus múltiples semejanzas, en resumen, permiten establecer algún tipo de filiación entre los relatos de Yepes y Avilés, pero hacen comprensibles las precauciones de Ramos al aventurar su vinculación al texto de Mesa, cautela

\footnotetext{
${ }^{25} \mathrm{El}$ cronotopo nocturno responde al simbolismo del astro rey como dios de la vida frente a la noche, donde la ausencia de la divinidad solar implica la llegada de la muerte, que dominará el mundo hasta la resurrección del dios a la mañana siguiente. Se trata del mitema que, en el centro y norte europeos, contempla al duro y oscuro invierno como el reino de la muerte, de ahí que, en la llegada del invierno (Samhain, más conocido como Halloween) creyesen que las puertas del inframundo quedaban abiertas para liberar a los difuntos y otros seres oscuros. Para Lisón Tolosana, "el cronotopo nocturno viene caracterizado por el modo saturniano y onírico, de sombras y crepuscular; su tiranía categorial nos introduce en el ámbito al que pertenecen otras realidades con otras coordenadas estratégicas. Estas presencias sólo tienden a manifestarse en registro nocturno, a la noche [...] pero convierten en imperioso y terco el motivo cronotópico, virtualmente insustituible en el folclore marcado por el pathos del terror. Se trata de un tiempo perenne, siempre idéntico e infinitamente repetido, tiempo otro que viene singularizado por la misteriosa irrupción de raras fuerzas extrañas, de potencias de otro mundo, del indescriptible más allá" (La Santa Compaña, 57); por su parte, Lecoteux señala que "L’Armée infernale passe de jour comme de nuit, on l'oublie trop souvent, mais les heures obscures l'emportent, expression des forces ténébreuses qui menacent les hommes avant le chant du coq. Son passage diurne est peut-être à rapprocher de midi, heure où surgit le démon du même nom" ("Chasse Sauvage", 21). Resulta imposible asociar a fuerzas demoníacas la aparición de las huestes del Cid y Fernán González en Las Navas, por lo que estas tropas que menciona Mesa en su poema estarían más cerca de las bíblicas señaladas por Ramos que de las centroeuropeas.
}

Medievalia 52:1, 2020, pp. 5-39 
que comparto con aún mayor escepticismo a la vista de las pruebas aportadas desde el análisis comparativo con la mitología celta. Y, aunque los dos héroes castellanos aparecen juntos en los textos, esto no resulta definitivo a la hora de vincular los tres testimonios, especialmente al considerar que entroncan con una tradición preexistente donde ya se los vincula, pues "a lo largo del siglo XV ambos personajes no sólo corren parejos en el ideal caballeresco castellano, sino que a ese ideal se había sumado ya su dimensión sobrehumana” (Ramos, "El Cid y Fernán González”, 59). Ejemplo evidente de ello es la Compilación de Milagros de Santiago, de Diego Rodríguez de Almela, quien dedica dos apartados a milagros jacobeos protagonizados, individualmente, por el Cid y Fernán González. Ninguno de los milagros tiene que ver con Las Navas, lo cual no significa que esta batalla quede excluida de la Compilación: se hace referencia a la misma al hablar de Alfonso VIII, y digo referencia porque, como bien observan Gutiérrez y López:

la batalla no se ve enriquecida sin embargo por ninguna intervención apostólica $[\ldots]$. La renuncia a integrar a Santiago apóstol en el combate no obedece sólo a la ausencia del Hijo de Trueno en la tradición cronística sobre este hecho: un panegírico del soberano, de las disposiciones de cruzada, de la unión de reyes ante el conflicto o de otros aspectos de la victoria de las Navas [... habrían impulsado sobradamente la idea de combate contra el infiel en el primer capítulo de esta serie a costa de reducir a términos insignificantes la referencia a Santiago ("La vocación jacobea", 61).

Frente a la imagen de los dos héroes como elegidos del Cielo para la Reconquista, existía un vacío narrativo con respecto a Santiago, partícipe en las batallas más trascendentales de la Reconquista, un hueco que sería cubierto por Fernán González y el Cid, cuya aparición tiene claramente el estilo de las protagonizadas por el apóstol. En este sentido, por tanto, aunque los tres testimonios reflejan la consolidación del Cid y Fernán González como modelos de la Reconquista a lo largo de los siglos XV y XVI, las fuentes del texto de Mesa se encuentran en las apariciones de Santiago en batalla, alejándose definitivamente de una relación stemmatica con los textos de Avilés y Yepes.

\section{UNA LEYENDA TARDÍA: EL REGRESO DEL HÉROE}

Las leyendas póstumas del Cid asociadas a Cardeña se transmitieron durante siglos, como demuestran las Antigüedades del padre Berganza, quien no se 
limitó a transmitir su relato sino que defendió su autenticidad con vehemencia. ${ }^{26}$ Pero la producción de leyendas cidianas de ultratumba no había cesado: en 1895, Víctor Balaguer publicó una de claros tintes becquerianos donde el protagonista es un Cid que recuerda mucho a la figura del cazador maldito, ${ }^{27}$ si bien se trata de una versión amable, en cuanto que Rodrigo no cabalga por estar maldito, sino para proteger a Burgos y Castilla en la Noche de Difuntos, cuando, según las creencias populares, los muertos se levantan para rondar por la tierra. La leyenda es la siguiente: ${ }^{28}$

\section{EL CUENTO DEL CID ${ }^{29}$}

A seis kilómetros de Burgos próximamente, pasado el pueblo de Villatoro y a la derecha de la carretera, se ve asomar, por entre un grupo de chopos lombardos, álamos, olmos y nogales, lo que existe en pie del que fue un día famoso monasterio de Fres del Val: su triste, viuda y solitaria espadaña, los robustos muros de la que fue su grandiosa iglesia, las viejas paredes que resguardan su claustro gótico florido, resto admirable de su antigua majestad.

Se levanta el monasterio en la falda de un monte que se parte en dos, como para darle abrigo y grato asiento. Parece abrirse en dos brazos que extiende por uno y otro lado cual si quisiera protegerle y estrecharle en ellos, o mejor, como si los abriera prolongándolos a uno y otro lado por el valle para que, desde las ventanas del edificio, se pudiera gozar del soberbio panorama que ante él se despliega.

${ }^{26}$ Sirva, verbigracia, su opinión sobre quienes negaban la veracidad de la victoria póstuma sobre Bucar: "No nos debiamos admirar, de que vn Moro viciàra con pueriles consejas las victorias, que han alcançado los Christianos Españoles con el patrocinio de Santiago: ni de que torciesse las palabras de la Historia para degollar la verdad: ni de que inventasse maquinas de suposiciones falsas para arruinar los sucessos maravillosos, porque redundan en descredito de la Secta, y de la passion de su obstinada ceguedad; pero que las niegue vn Catolico, y finja ideas ridiculas, para que no las creamos, y para que no las contemos entre los singulares beneficios, que hemos recibido de Santiago, causa admiracion, y nos maravillamos, que en este tiempo se escrivan tales cosas con tanta serenidad, y satisfacion" (Antigüedades, I, 539).

${ }^{27}$ Junto a la procesión de muertos y la cabalgata celeste, existen manifestaciones individuales de la Cacería Salvaje, esto es, donde no se presenta un ejército, sino la figura de un único cazador (el diabólico, el maldito, el fantasmal...).

${ }^{28}$ Agradezco a mi querida amiga y reconocida periodista Patricia Ansótegui Barrera que me descubriese esta leyenda, de la cual ignoraba su existencia hasta hace poco, y que tan interesante resulta para los propósitos del presente estudio.

${ }^{29}$ Cito el texto a partir de su primera edición. He actualizado el uso de tildes y guiones, así como el de mayúsculas y minúsculas, además de corregir los signos de puntuación cuando ha sido necesario para ofrecer una lectura más cómoda.

Medievalia 52:1, 2020, pp. 5-39 
Fres del Val es hoy una verdadera ruina que, por fortuna, parece haber encontrado quien se ocupe en ella para restaurarla.

Muy cerca de Fres del Val está el Vivar del Cid, que recuerda las mocedades de aquel héroe legendario, $y$, a muy cortas distancias, tiene también otros sitios de honradas y memorables tradiciones en los anales de la vieja Castilla.

Junto a la puerta de la que fue iglesia, a la derecha, hay el monte al que se sube por una cuesta que se llama de la Reina, y acerca del cual existe una dramática leyenda que contaré otro día.

A su izquierda se halla el otro monte, a cuya cima conduce otra cuesta que se llama de los Grillos. La meseta de este monte tiene una vasta extensión, llana, fácil, cómoda, especie de paseo enyerbado que se prolonga tres o cuatro kilómetros al menos sin que el menor accidente ni la menor ondulación del terreno pueda interrumpir ni alterar el paso tranquilo del caminante o el soberbio galope del caballo.

Por un lado, extiende este monte su llanada hasta llegar a un cabezo desde donde se puede ver, en lo hondo, como a los pies, todo el territorio que rodea a Burgos: el cerrete en cuya cima se alza la cartuja con sus líneas de ataúd y los pináculos en forma de fúnebres blandones que la rodean; las Huelgas, famosas y tan renombradas, cuyas monjas eran damas palatinas y, sus abadesas, reinas soberanas; las ruinas del castillo burgalés, que tan ruda resistencia opuso a los Reyes Católicos, y los grandes paseos de sombrosos árboles que hoy ciñen con rico cinturón de follaje a la ciudad que fue sede de primates, cámara de reyes y cabeza de Castilla.

Por el lado es por donde la meseta se extiende y prolonga, siempre sembrada de menuda y olorosa hierba, que es alfombra tendida a los pies del caminante, el cual puede deleitar su vista con la de peregrinos paisajes, viendo tenderse en el fondo del valle, y entre florestas, los pueblos de Quintanilla, Vivar del Cid, Soto Palacios, Cercedilla, Villaverde y otros muchos.

Esta es la meseta de la leyenda, la del cuento del Cid

Y esta leyenda hela aquí, desnuda, sencilla, escueta, con toda su nebulosidad, todo su misterio y todo su romanticismo. Hela aquí, tal como hube yo de recogerla de labios de un octogenario que fue, en sus buenos tiempos, mozo de espuela al servicio y mandato de los monjes de Fres del Val.

Todos los años, el Día de Difuntos, que es, según parece, aquél en que se da huelga a los muertos, promediada ya la noche, un caballero, vistiendo mallas, ciñendo yelmo y embrazando escudo, jinete en su caballo encubertado, va subiendo lentamente, solapado por las sombras, la cuesta que conduce a la meseta. Una vez en ella, el misterioso jinete se dirige al cabezo y, a guisa de atalayador vigía, pasea su vista por las cercanías de Burgos, abrazando y acariciando 
con su mirada toda la vasta extensión de dormida tierra que se distingue desde el cabezo, como si pretendiera desvelarla con el rayo de sus ojos. En seguida, virando su caballo y aplicándole la espuela, se lanza a una carrera desesperada todo lo largo de la meseta, que recorre unas veces al trote y otras a escape, como si fuese aquel sitio arena de palenque dispuesto para militares ejercicios de torneo, hasta llegar el momento en que, fatigados ya cabalgante y cabalgadura, se asoma de nuevo al cabezo, se detiene unos instantes, arroja su postrer mirada, que encamina a Burgos, y, pausadamente, indolente o tardo, deshace su camino, baja la cuesta y, en uno de sus recodos, desaparecen de repente corcel y caballero, como tragados por la tierra.

Esto sucede todos los años en la Noche de Difuntos. Siempre el mismo paladín con su mismo caballo, el mismo paseo, la misma detención ante Burgos, que asoma a lo lejos, la misma desenfrenada carrera por el enyerbado llano de la cumbre, y el mismo repentino desaparecimiento:

—Pero esto, ¿quién lo ha visto? — pregunté al cuentista que, candorosamente, me relataba el suceso.

-Yo - me contestó como la cosa más natural del mundo.

Le miré con asombro. Hubo de advertirlo en el acto, $y$, como si quisiera darme la clave del misterio por medio de una razón concluyente y de un argumento sin réplica, se apresuró a añadir:

—Este caballero es el Cid. Cada año, al llegar la Noche de Difuntos, sale de su sepulcro, monta en su caballo y sube a esta cumbre para ver su Vivar, su Burgos, sus tierras de Castilla, y cuando lo ha visto, cuando está ya seguro de que su Castilla vive y se conserva, se vuelve tranquilamente a su fosa.

El buen hombre hubo de notar en mí señales de incredulidad y, antes de que yo pudiese tomar la palabra, prosiguió diciendo:

-Yo le vi. ¡Cuando digo que yo le vi con estos ojos que se ha de comer la tierra...! Hace muchos años, antes del 35, estando aún los monjes en su claustra, siendo yo muy joven, contáronme el suceso. Al llegar el primer Día de Difuntos, por la noche, que era, por cierto, muy negra y tempestuosa, salí para verlo, me agazapé bajo una mata cerca de la cuesta de los Grillos, y, entre una y dos de la madrugada poco más o menos, vi pasar a lo lejos, como una sombra, el caballero y el caballo subiendo la cuesta. Llevaba él una lanza en la mano. Yo lo vi. Apoderóse un temblor de todo mi cuerpo, mis dientes daban unos con otros como castañuelas de gitana, y me fui todo lo más de prisa que pude, andando a gatas y por lo hondo, sin ni siquiera volver la cabeza.

—Pero se le ocurriría volver al año siguiente, ¿verdad? —le dije-.

-No, jamás. Dios me libre. Me confesé con el P. Cristóbal, que era un santo varón, y me dijo que, pues Dios me había concedido verlo una vez, no 
me ocurriera en jamás intentar verlo por segunda, pues podría cegar de repente. Y no volví.

—Pero, hombre de Dios —le dije—, ¿Quién le asegura que aquella sombra que vio en medio de su terror, aquel jinete con lanza, no fuese un viajante madrugador o retardado que iba su camino, o tal vez un colono que, con su aguijada en ristre, se dirigía a su boyera? No crea usted en brujas. No crea usted esto.

-Es que quiero creerlo - me contestó, irguiéndose como si fuese héroe de tragedia-. Yo creo firmemente, jasí Dios me salve!, que es el Cid que viene todos los años a ver su Castilla, así como creo que, si ésta se perdiese un día, el Cid volvería para libertarla.

Parecióme inhumano contradecir al buen viejo y bajé la cabeza en señal afirmativa, cual si me arrepintiera de haber tenido un momento de duda.

Hay que admirar el patriotismo donde quiera que brote y en la forma que se presente.

Y nada más.

Éste es el cuento. ¡Ah! Si no fuese español, si fuese del norte, en una palabra, si fuese de Ibsen, iqué de lecciones de patriotismo, qué de maravillosas cosas y qué de aturdidores simbolismos se encontrarían en él!

Resulta difícil saber si Balaguer puso por escrito una leyenda oral o si se trata de una invención literaria, pero, de todos modos, registra influencias evidentes de las Leyendas becquerianas. Especialmente, se perciben ecos de “El Monte de las Ánimas”, donde aparece el tema de los caballeros fantasmales que se levantan de sus tumbas en la Noche de Difuntos, lo que, en efecto, constituye el tema de "El cuento del Cid" y, si los fantasmas rondan por el Monte de las Ánimas en el relato de Bécquer, Balaguer escoge una meseta como escenario de las apariciones del Cid. Tampoco pueden obviarse influencias de "El Miserere", especialmente en lo concerniente a los monjes que informaron sobre la aparición del Cid al anciano testigo, y que éste marchase en busca del espectro en una noche de tormenta - de nuevo, el cronotopo nocturno-, del mismo modo que el romero músico partió a encontrarse con los fantasmas cantores del Miserere de la Montaña en una noche tempestuosa tras descubrirlo de labios del hermano lego y los pastores que le dieron cuenta de tal portento. También se percibe la huella de "El Miserere" cuando el anciano revela que, al ver al Cid, "apoderóse un temblor de todo mi cuerpo, mis dientes daban unos con otros como castañuelas de gitana", lo cual recuerda a la reacción del músico romero, pues, ante la visión de los monjes espectrales, "sus nervios saltaron al impulso de una conmoción fuertísima, sus dientes 
chocaron, agitándose con un temblor imposible de reprimir, y el frío penetró hasta en la médula de los huesos" (Bécquer, "El miserere”, Leyendas, 182).

Estructuralmente, "El cuento del Cid" coincide con esta última leyenda, en cuanto que el relato no se inicia enseguida, sino que va precedido de una introducción donde se describe el escenario de la narración, y contiene, también, un epílogo en primera persona donde el autor reflexiona acerca de la leyenda que acaba de plasmar. Resulta interesante observar que, en dicho apartado de cierre, el anciano testigo revela que él mismo vio al espectro del Cid y relata su experiencia, lo que coincide con el final de "El Monte de las Ánimas”, donde un cazador explica cómo vio a los templarios alzarse de sus tumbas y a Beatriz, enloquecida, huir acosada por un caballero espectral, claramente identificable como un cazador diabólico. ${ }^{30}$

"El cuento del Cid" registra, sin embargo, una diferencia importante con "El Monte de las Ánimas" y "El Miserere”: frente a las apariciones masivas, el texto burgalés se limita a la del Campeador. También en Bécquer aparecen fantasmas solitarios: "La cruz del diablo" refiere la historia de un terrible caballero fantasmal, responsable de atroces crímenes, inspirado probablemente en la leyenda del conde Arnaldos o comte Arnau (Benítez, Bécquer tradicionalista, 163, 174-175), cuyo nombre entronca con el del caudillo de la Mesnie Hellequin (Delpech, "Le chevalier-fantôme", 73) y que Lecouteux identifica con el temible fantasma del cazador maldito (Chasses fantastiques, 72-73), aunque los desmanes que comete el espectro becqueriano le acercan más al cazador diabólico, clasificación perfectamente extensible al jinete que persigue a Beatriz al final de "El Monte de las Ánimas”, teniendo en cuenta que estaría inspirado en el fantasma de Guido de Anastagi del Decamerón (Perrus, "Chasse infernale"). ${ }^{31}$ Como se aprecia, aunque se aparece en solitario, este Cid no se corresponde con el cazador maldito sino que, más bien, es una prolongación del Cid que fue en vida, un caballero noble que protege su tierra. Además, los cazadores diabólicos inspiran pavor por ser fantasmas violentos, mientras que el Cid infunde terror por su condición fantasmal, no por su agresividad guerrera, hasta el punto de que el testigo desea creer que vio algo real, pues eso significa que Burgos está amparado por el Campeador.

\footnotetext{
${ }^{30}$ El cazador diabólico aparece normalmente persiguiendo a una o varias mujeres, mientras que el cazador maldito es aquel que cabalga eternamente por haberse atrevido a cazar en un día sagrado o haber practicado la caza en terreno sagrado, en domingo o un día consagrado a Dios (Lecouteux, "Chasse Sauvage”, 17-18). Este último también aparece encarnado por Teobaldo en la leyenda becqueriana "Creed en Dios", donde la descripción de las tropas angélicas, por cierto, recuerda muchísimo a la Wild Hunt.

${ }^{31}$ Benítez no distingue al cazador diabólico del maldito, etiquetando a ambos como este último (Bécquer tradicionalista, 163-176).
} 
Esta vigilancia del Cid implica la aparición de un nuevo tópico en este recorrido por las leyendas de ultratumba del Cid: el mito del eterno retorno, por el que se niega la muerte del héroe, quien descansa o duerme en espera de volver cuando su pueblo lo necesite (motivo A580 del Motif Index de Thompson). ${ }^{32}$ La manifestación más conocida de este mito es la del rey Arturo, quien, mortalmente herido en la batalla de Camlann, curó sus heridas en Avalón gracias a su hermana Morgana, y allí permanecerá hasta que Inglaterra necesite de nuevo a su antiguo monarca. Una variante de este motivo es el D1960.2 Kyffhaüser del índice de Thompson, "King asleep in mountain (Barbarossa, King Marko, Holger Danske, etc.) will awake one day to succor his people". Todos los monarcas y héroes que menciona Thompson descansan en cuevas situadas en montañas, de ahí el nombre del motivo, Kyffhaüser, la colina donde el folklore local sitúa el lugar donde descansa el emperador Federico Barbarroja (Ashe, "Cave Legend”, 77; Freed, Frederick Barbarossa, especialmente 521-523). El propio Arturo presenta una variante por la que reposa en una cueva (Barber, King Arthur, 65-67; Green, Arthuriana, 110; Ashe, "Cave Legend”, 76-77), y así también le sucede al rey Marko Mrnjavčević (Low, The Ballads, 183); Ogier el Danés, por su parte, duerme bajo el castillo de Kronborg, Dinamarca (Mrs. Bushby, "A visit to Denmark", 59). A ellos deben sumarse tanto el ejército que duerme bajo el Blaník y que, comandado por san Wenceslao, salvará a la República Checa cuando se encuentre en peligro (Horák, "Remarks”, 254-258), como el emperador Carlomagno, cuyos restos descansan en Aquisgrán, hecho que no ha sido óbice para atribuirle sepulturas en el Untersberg o el Odensberg (Lyncker, Deutsche Sagen, 5-7). En este sentido, resulta llamativo que el Cid abandone su sepultura para cabalgar por una meseta $y$ que, al terminar, desaparezcan "corcel y caballero, como tragados por la tierra".

En ese aspecto, la inscripción de la tumba del Cid adquiere un renovado sentido (Crónica del famoso cavallero, 678):

\section{QUANTUM ROMA POTENS BELLICIS EXTOLLITUR ACTIS: VIUAX ARTURUS FIT GLORIA QUANTA BRETANIS NOBILIS E CAROLO QUANTUM GAUDET FRANCIA MAGNO: TANTUM IBERIA DURIS CID IMBITUS CLARET. ${ }^{33}$}

32 “Culture hero's (divinity) expected return. Divinity or hero is expected to return at the proper time and rescue his people from their misfortunes".

${ }^{33}$ La libre traducción de la Crónica particular reza como sigue: "Que bien así como Roma, que es noble cibdad e poderosa, fue ensalçada e enoblescida por muchas batallas e muchos buenos fechos que los romanos fizieron, o así como en Bretaña los bretones viven en gran gloria creyendo que el rey Artús es vivo, o así como la noble Francia se glorifica por el rey Carlos 
Como estos dos héroes, el Cid no está completamente muerto, sino que aguarda el momento de volver cuando Burgos necesite su ayuda, lo cual, por cierto, remite al episodio del Cid embalsamado a quien el judío intentó mesar la barba: en efecto, parece una variante de A580, pues la reacción del Cid al extraer su espada, como si estuviese alerta, lo sitúa en esa especie de letargo entre la vida y la muerte, si bien el tópico recibe el conveniente tratamiento cristiano para convertir el relato en un milagro.

\section{Conclusiones}

El análisis diacrónico de las leyendas post mortem del Cid muestra una clara evolución de las mismas, configuradas a partir del pensamiento de cada época: los primeros testimonios muestran a un cadáver que sirve como núcleo de unos relatos de índole hagiográfica para acabar, en las leyendas posteriores, convirtiéndose en un espectro. Aparte del relato donde el padre e hijo de Rodrigo se le aparecen en sueños, la evolución del Cid fantasmal es comprensible desde una lectura histórica: en la Leyenda de Cardeña, el protagonista no es un espectro sino el cuerpo mismo del Cid porque el monasterio de San Pedro de Cardeña custodiaba sus restos y, como si de las reliquias de un santo se tratase, convenía mostrarlos como foco de unos milagros. Transcurridos varios siglos, cuando ya no hay cadáver que mostrar ni trasladar al campo de batalla, el Cid aparece en Las Navas de Tolosa con Fernán González convertido en espectro, pues es el único modo en que puede ya combatir, pero con un aura de santidad, pues ambos actúan en substitución del apóstol Santiago.

Ya en el neorromanticismo, y acorde al gusto de esta corriente por lo terrorífico, el Cid pierde sus rasgos sagrados para convertirse en objeto de horror por el mero hecho de ser un fantasma y no por actuar de manera amenazante o violenta. En fin, da miedo por sí mismo, como sucedía a quienes rechazaban al monstruo de Frankenstein según nos cuenta Mary Shelley, pues quedaban espantados ante su pavorosa presencia, aunque la desgraciada criatura se comportase de manera pacífica.

La versión neorromántica del espectro del Cid, heredera del movimiento decimonónico, guarda similitudes con algunas de las grandes leyendas de Gustavo Adolfo Bécquer, referente obligatorio del romanticismo español. Los

el Grande, bien assí maravillosamente España, que es llamada Iberia, nombrada de Ebro, e todos los castellanos que son de duros e fuertes coraçones son enoblescidos e ensalçados e ganaron prez e honra por el noble e muy famoso Cid” (Crónica del famoso cavallero, 678).

Medievalia 52:1, 2020, pp. 5-39 
aparecidos de varios relatos del genio sevillano corresponden a los diferentes tipos de espectro que adopta el Cid a lo largo de su evolución, como el cuerpo embalsamado equivalente a las estatuas animadas por espíritus o los ejércitos de ultratumba. Este dato es muy interesante, pues revela cómo Bécquer plasmó en sus páginas una variedad de fantasmas que no se inventó, sino que perpetuó, ya que tenían raíces muy antiguas, como atestiguan no ya los textos cidianos, sino también los que han servido para contrastar y comprender mejor dichos testimonios. En ese sentido, también, no puede hablarse de originalidad en las leyendas póstumas del Cid, sino de la adaptación de diversos tipos de espectro y tradiciones: a las influencias carolingias y árabes es necesario incluir ahora otras centro y noreuropeas, como la Wild Hunt, en las leyendas póstumas cidianas medievales, o ciertas reminiscencias del cazador maldito en "El cuento del Cid", aunque, en este caso, la transmisión no tiene por qué deberse a una influencia directa del folklore europeo, sino a la inspiración de las Leyendas becquerianas. De todos modos, quiero llamar la atención sobre el especial caso de la reacción del cadáver del Cid para defenderse del judío como variante de las estatuas funerarias que cobran vida, lo que, aparte de original, remite a una combinación de tradiciones.

Por otra parte, estos relatos sirven como una alternativa a los dedicados a las mocedades del héroe: si éstas servían para dilatar la historia y leyenda de Rodrigo Díaz hacia su infancia cuando el filón de su heroica vida adulta parecía agotado, las leyendas que aquí hemos revisado constituyen su polo opuesto al prolongar el mito no hacia la infancia, sino tras la vida terrena del Cid. Esta expansión aún no ha terminado, pues, recientemente, José Antonio Molero ha publicado un relato titulado "El Cid vela por Burgos", claramente inspirado en el relato de Balaguer, donde el anciano testigo es reemplazado por un pastor y un peregrino, y donde se da voz propia al espectro, quien se presenta afirmando que “yo, Don Rodrigo Díaz de Vivar, velo por Burgos y por Castilla”, revelación que frustra toda la atmósfera de misterio que Balaguer logra recrear. Aunque, en este aspecto, cabe señalar que esta deturpación de la leyenda burgalesa recupera a los aparecidos parlantes que se presentaron ante San Isidoro de León y San Salvador de Oviedo, conversación también habitual en las manifestaciones de la Wild Hunt y no tanto del cazador maldito.

Un asunto más complejo es resolver la fortuna de estas leyendas entre el gran público: hoy en día, muchos de estos relatos son desconocidos por la mayoría de la gente, a excepción de la victoria después de muerto contra Bucar. La diferencia crucial entre esta leyenda y las demás, en mi opinión, radica fundamentalmente en su importancia en El Cid (1961), película dirigida por Anthony Mann y protagonizada por Charlton Heston y Sofía Loren que, a nivel global, difundió la figura del Cid, y donde su última batalla 
sirve de colofón a todo el filme, lo cual le otorga especial relevancia, dejando una especial huella en la memoria del gran público al igual que la película $E l$ guerrero $n^{0} 13$ ha popularizado la oración vikinga antes referida. Por ello, la antigüedad de las leyendas no es un obstáculo para triunfar en la actualidad, pero, ciertamente, y aparte de la evolución de la figura del Cid — sea vivo o muerto-, también su transmisión debe ir acorde a cada época, por lo que estos relatos sólo alcanzarán popularidad si utilizan los medios de difusión más efectivos hoy en día. De todos modos, tras casi un milenio de evolución, resulta obvio que el Cid sigue cabalgando sobre Babieca ... a tumba abierta.

\section{BiBLIOGRAFÍA}

Ashe, Geoffrey, “Cave Legend”, en Norris J. Lacy (ed.), The New Arthurian Encyclopedia, New York \& London: Garland Publishing, 1996, 76-77.

Balaguer, Víctor, “El cuento del Cid”, En Burgos, Madrid: El Progreso, 1895, 259-269. BARber, Richard, King Arthur in Legend and History, London: Sphere Books, 1973. BÉCQUer, Gustavo Adolfo, Leyendas, edición, prólogo y notas de Joan Estruch con un estudio preliminar de Russell P. Sebold, Barcelona: Crítica, 1994.

BeníteZ, RubÉn, Bécquer tradicionalista, Madrid: Gredos, 1971.

Berganza, Francisco de, Antigüedades de España, propugnadas en las noticias de sus reyes y condes de Castilla la Vieja, en la historia apologética de Rodrigo Díaz de Bivar, dicho Cid Campeador, y en la corónica del Real Monasterio de San Pedro de Cardeña, 2 vols., Madrid: Francisco del Hierro, 1719-1721.

Boix Jovaní, Alfonso, “La 'Cacería fantástica' en El Monte de las Ánimas”, Revista de Folklore, 424, 2017, 9-15.

Bushby, Mrs., "A Visit to Denmark and Sweden in the Autumn of 1862. Part II", Bentley's Miscellany, LIV, London: Chapman and Hall, 1963, 57-67.

Cantar de Mio Cid, edición, estudio y notas de Alberto Montaner Frutos con un ensayo de Francisco Rico, Madrid: Real Academia Española-Barcelona: Galaxia Gutenberg, 2011 (primera edición en Barcelona: Crítica, 1993; reed. Barcelona: Galaxia Gutenberg-Círculo de Lectores, 2007).

Chanson de Roland, texto original, traducción, introducción y notas por Martín de Riquer, Barcelona: Acantilado, 2003.

Conde, Juan Carlos, "La difusión y las fuentes de un episodio cronístico sobre el Cid”, Boletín de la Real Academia Española, 67, 1987, 109-136.

Crichton, Michael, Devoradores de cadáveres, Barcelona: Plaza \& Janés, 1993.

Crónica de Castilla, édition et présentation de Patricia Rochwert-Zuilli, Paris: SEMHSorbonne [Les Livres d'e-Spania], 2010. 
Crónica del famoso cavallero Cid Ruy Díez Campeador, en Mio Cid Campeador, edición e introducción de José María Viña Liste, Madrid: Fundación José Antonio de Castro, 2006, 119-690.

Crónica de veinte reyes, Burgos: Ayuntamiento, 1991.

Crónica de 1344, edición crítica y estudio. Tesis doctoral de Ingrid Vindel Pérez dirigida por Inés Fernández-Ordóñez y Francisco Rico Manrique, Bellaterra: Universitat Autònoma de Barcelona, 2015 [tdx.cat/bitstream/handle/10803/386537/ invilde1.pdf, consultada el 3 de diciembre de 2019].

Delpech, François, "Le chevalier-fantôme et le maure reconnaissant. Remarques sur la légende de Muño Sancho de Finojosa”, en Philippe Walter (ed.), Le mythe de la Chasse sauvage dans l'Europe médiévale, etudes réunies et présentées par Philippe Walter avec la collaboration de Claude Perrus, François Delpech, Claude Lecouteux, Paris: Honoré Champion, 1997, 73-123.

Don Juan Manuel, Crónica abreviada, en Obras completas, edición de Carlos Alvar y Sarah Finci, Madrid: Fundación José Antonio de Castro, 2007, 7-297 (Biblioteca Castro).

DuRÁN, Agustín, Romancero general, ó Colección de romances castellanos anteriores al siglo XVIII, Madrid: M. Rivadeneyra, 1859.

Entwistle, William J., "La Estoria del noble varón el Cid Ruz [sic] Díaz el Campeador, Sennor que fué de Valencia”, Hispanic Review, 15:1, 1947, 206-211.

Estruch Tobella, Joan, “Fuentes y originalidad en 'El beso', de G. A. Bécquer”, Revista Hispánica Moderna, 47:1, 1994, 5-14.

Freed, John B., Frederick Barbarossa: The Prince and the Myth, New Haven-London: Yale University Press, 2016.

GAlmÉs de Fuentes, Álvaro, "La batalla vencida después de la muerte. La leyenda del Cid y la tradición árabe", Revista de Filología de la Universidad de La Laguna, 17, 1999, 309-312 (reed. con mínimas modificaciones en su libro La épica románica y la tradición árabe, Madrid: Gredos, 2002, 363-365).

García-Viñó, Manuel, Mundo y trasmundo de las leyendas de Bécquer, Madrid: Gredos, 1970.

Green, Thomas, Arthuriana. Early Arthurian Tradition and the Origins of the Legend, Louth: The Lindes Press, 2009.

Gutiérrez García, Santiago y Santiago López Martínez-Morás, "La vocación jacobea de Diego Rodríguez de Almela”, Ad limina: revista literaria del Camino de Santiago y las peregrinaciones, 4, 2013, 39-67.

Historia Latina de Rodrigo Díaz de Vivar, edición, traducción y estudios de José Manuel Ruiz Asencio e Irene Ruiz Albi, estudio preliminar de Gonzalo Martínez Díez, Burgos: Ayuntamiento-Caja de Burgos, 1999.

HorÁk, JirI, "Remarks on the Relation between Folktales and Legends”, Fabula, 9, 1967, 254-258. 
Houston, Susan Hilary, “Ghost Riders in the Sky”, Western Folklore, 23:3, 1964, 153-162.

Joset, JacQues, “Sueños y visiones medievales: razones de sinrazones”, Atalaya, 6, 1995, 51-70.

Kelly, SeAn, "The 13th Warrior Created a New Viking Mythology We See Everywhere”, Escapist Magazine, 21, September 2019 [escapistmagazine.com/ v2/the-13th-warrior-created-a-new-viking-mythology-we-see-everywhere/, consultado el 18 de diciembre de 2019).

LACOMвA, MARTA, “Trois miracles cidiens et un motif hagiographique. La mise en place d'un système narratif dans la Crónica abreviada de l'infant don Juan Manuel”, en Miracles d'un autre genre. Récritures médiévales en dehors de l'hagiographie, études réunies par Olivier Biaggini et Bénédicte Milland-Bove, Madrid: Casa de Velázquez, 2012, 171-184.

Lara Ramos, Luis Fernando (dir.), Diccionario del español de México, México: El Colegio de México, Centro de Estudios Lingüísticos y Literarios, 2010, volumen I.

Lecouteux, Claude, "Introduction”, en Philippe Walter (ed.), Le mythe de la Chasse sauvage dans l'Europe médiévale, etudes réunies et présentées par Philippe Walter avec la collaboration de Claude Perrus, François Delpech, Claude Lecouteux, Paris: Honore Champion, 1997, 9-12.

Lecouteux, Claude, "Chasse Sauvage / Armée Furieuse: réflexions sur une légende germanique”, en Philippe Walter (ed.), Le mythe de la Chasse sauvage dans l'Europe médiévale, etudes réunies et présentées par Philippe Walter avec la collaboration de Claude Perrus, François Delpech, Claude Lecouteux, Paris: Honoré Champion, 1997, 13-32.

Lecouteux, Claude, Chasses fantastiques et cohortes de la nuit au Moyen Age, Paris: Imago, 1999.

Lisón Tolosana, CARmelo, La Santa Compaña. Fantasías reales, realidades fantásticas, Madrid: Akal, 2004.

LynCKer, KarL, Deutsche Sagen und Sitten in hessischen Gauen, Kassel: Oswald Bertram, 1854.

Menéndez Pidal, Ramón, “Estantigua”, Revue Hispanique, 7:21-22, 1900, 5-9.

Michaëlis de Vasconcelos, Carolina, “Réplica”, Revue Hispanique, 7:21-22, 1900, 10-19.

Molero, José Antonio, “El Cid vela por Burgos”, Gibralfaro, 72, 2011, 15.

Montaner Frutos, Alberto, "El epitafio épico", en Actas del IX congreso internacional de la Asociación Hispánica de Literatura Medieval (A Coruña, 18-22 de septiembre de 2001), A Coruña: Toxosoutos, 2005, 193-203.

Montreuil, Gerbert De, La Continuation de Perceval, édité par Mary Williams, I, Paris: Librairie Ancienne Honoré Champion, 1922.

Medievalia 52:1, 2020, pp. 5-39 
Myers, Frederick William Henry, Human Personality and Its Survival of Bodily Death, London: Longmans, Green \& Co., 1903.

PAGE, R. I., Mitos nórdicos, $3^{\text {a }}$ ed., traducción de José Ángel Fernández Canosa, (1 ${ }^{\text {a }}$ ed. 1994; 2a ed. 1999; ed. original: Norse Myths, London: The Trustees of the British Museum, 1990), Madrid: Akal, 2007.

Perrus, Claude, “La 'Chasse Infernale': des exempla à la nouvelle V,8 du Décaméron”, en Philippe Walter (ed.), Le mythe de la Chasse sauvage dans l'Europe médiévale, etudes réunies et présentées par Philippe Walter avec la collaboration de Claude Perrus, François Delpech, Claude Lecouteux, Paris: Honoré Champion, 1997, 125-139.

Poema de Fernán González, edición de Juan Victorio, Madrid: Cátedra, 1981.

Primera Crónica General. Estoria de España que mandó componer Alfonso el Sabio y se continuaba bajo Sancho IV en 1239 publicada por Ramón Menéndez Pidal, tomo I: Texto, Madrid: Bailly-Bailliere é hijos, 1906.

RAmíreZ Del Río, José, La Leyenda de Cardeña y la épica de Al-Andalus. La victoria póstuma del Cid, Sevilla: Signatura Ediciones de Andalucía, 2001.

Ramos, Rafael, "El Cid y Fernán González en las Navas de Tolosa”, en Lara Vilà (ed.), Estudios sobre la tradición épica occidental (Edad Media y Renacimiento), Seminario de Poética del Renacimiento de la Universitat Autònoma de Barcelona-Instituto de Estudios Clásicos Lucio Anneo Séneca de la Universidad Carlos III de Madrid, Bellaterra-Madrid: Caronte, 2011, 53-63.

Rodríguez López, Pablo, "El sol parado de la Chanson de Roland. Transmisión e influencias", Hápax: Revista de la Sociedad de Estudios de Lengua y Literatura, 12, 2019, 57-65.

Ryan, J. S., "Othin in England: Evidence from the Poetry for a Cult of Woden in Anglo-Saxon England”, Folklore, 74:3, 1964, 460-480.

Smith, Colin, "The Cid as Charlemagne in the Leyenda de Cardeña”, Romania, 97:388, 1976, 509-531.

Sмith, Colin, "Leyendas de Cardeña”, Boletín de la Real Academia de la Historia, 179:3, 1982, 485-523.

The Ballads of Marko Kraljević, translated by D. H. Low, Cambridge: Cambridge University Press, 1922.

Thompson, Stith, Motif-Index of Folk-Literature. A Classification of Narrative Elements in Folktales, Ballads, Myths, Fables, Mediaeval Romances, Exempla, Fabliaux, Jest-Books, and Local Legends, 6 vols., Bloomington \& Indianapolis: Indiana University Press, 1955-1958.

VÀrvaro, Alberto, Apparizioni fantastiche. Tradizioni folcloriche e letteratura nel medioevo, Bologna: Il Mulino, 1994.

Walter, Philippe, "Hellequin, Hannequin et le Mannequin”, en Philippe Walter (ed.), Le mythe de la Chasse sauvage dans l'Europe médiévale, etudes réunies et

Medievalia 52:1, 2020, pp. 5-39 
Alfonso Boix Jovaní

présentées par Philippe Walter avec la collaboration de Claude Perrus, François Delpech, Claude Lecouteux, Paris: Honoré Champion, 1997, 33-72.

Yepes, Antonio de, Crónica general de la Orden de San Benito, Madrid: Atlas, 19591960. 
